\title{
Case Study of Concrete Surface Design and Construction Method for Freeform Building Based on BIM -Focused on Tri-Bowl, Korea-
}

\author{
Ryu, Han-Guk ${ }^{1 *}$ \\ Kim, Sung-Jin ${ }^{2}$ \\ Department of Architectural Engineering, Changwon National University, Changwon, GyeongNam-Do, 641-773, Korea ${ }^{1}$ \\ Withworks, Seokchon-Dong 15-1 Songpa-Gu, Seoul, 138-842, Korea ${ }^{2}$
}

\begin{abstract}
While it is generally possible to install curved panels manufactured in a factory within the permitted error range on an irregular surface frame of concrete or steel, it is difficult and expensive. Freeform architecture is thus designed and constructed differently from formal buildings. In order to more easily and inexpensively actualize freeform architecture, Building Information Modeling (hereinafter referred to as BIM) has recently been applied in the construction industry. However, the related research and case analyses are not sufficient to identify the implications and contributions of freeform buildings in future similar projects. Therefore, this research will study design and construction methods for freeform surfaces, particular the concrete surface frame of freeform buildings based on BIM, focused on the Tri-Bowl project. This study attempts to analyze the pros and cons of each method for the concrete surface frame of the Tri-Bowl, and then presents the lessons learned and implications related to the design and construction process of the freeform architecture. Several implications for design and construction of concrete surface frame of the freeform building, the Tri-Bowl, are found. The first is that manufacturing and installation of a curved concrete frame is precisely performed based on the exact numerical values of materials and installation made using BIM 3D technologies, such as CATIA and Rhino. The second is that close and continuous collaboration among the different participants in the construction of the Tri-Bowl allowed them to cope with virtual conditions. The third is that design and construction processes have changed, and high quality of the surface frame of a freeform building is required.
\end{abstract}

Keywords : BIM(Building Information Modeling), freeform, the tri-bowl, 3d modeling, CATIA, mock-up, concrete surface frame

\section{Introduction}

Roof and exterior wall are designed and constructed in a manner that prevents the accumulation of water within the wall and roof assembly in the formal building. However, in a freeform building there is no clear distinction between exterior wall and roof. In other words,

Received : June 1, 2011

Revision received : February 10, 2012

Accepted : February 17, 2012

* Corresponding author: Ryu, Han-Guk

[Tel: 82-55-213-3804, E-mail: hgryu@changwon.ac.kr]

(c)2012 The Korea Institute of Building Construction, All rights reserved. the exterior walls and roof systems of the freeform building are integrated as a surface, unlike the formal building envelope.

It is generally possible to install curved panels manufactured in a factory within the permitted error range on an irregular surface frame of concrete or steel frame, but it is difficult and expensive. Hence the techniques by which products, components, or assemblies are designed and manufactured heavily involve the use of computer-aided design and fabrication for manufacturing processes.

In contemporary architectural practice, flat sections and plan drawings are no longer a primary 
means of representation and communication with participants. Nowadays, the widely used media in architecture include visualizations, animations and three-dimensional models[1].

CAM (Computer Aided Manufacturing) software, wherein the user specifies how the design model is to be actually manufactured, creates a series of digital instructions for controlling specific machines. One or more computer numerically controlled (CNC) machines and other related tools are used to translate these digital instructions into actual machine operations that make the objects[2].

In particular, freeform architecture involves a different approach to design and construction from a formal building. To actualize freeform architecture, BIM (Building Information Modeling, hereinafter referred to as BIM) has recently been applied in the construction industry. However, the related studies and case analyses are currently not sufficient to identify the implications and contributions of the freeform buildings for future similar projects.

Therefore, this research will study a design and construction method based on BIM for freeform surfaces, particularly the concrete surface frame of freeform buildings, focused on the Tri-Bowl project. The Tri-Bowl is a sculptural structure that commemorates the global fair \& festival of 2009 in Incheon Song-Do in Korea.

\section{Previous research}

Previous research related to BIM and freeform design and construction can be summarized as follows.

Kim et al.[3] focused on how to use parametric technology in architectural design, and how to test the fabrication possibilities of freeform structures. Park et al.[4] determined that BIM tools and analysis applications can be used to perform a solar/sun study, daylighting analysis, interior illuminance analysis, insulation analysis and fluid dynamics analysis during the design stage, and can supply the envelope design.

Park and Lee[5] explored the possibility of solving the difficulties involved in non-linear forms by incorporating BIM and 3D-based and object-oriented techniques. Park and Jun[6] suggested a methodology for a generative technology of form in freeform architecture through PQ(Planar Quadrilateral) mesh.

Research on freeform architecture is promoted by the Smart Geometry group (www.smartgeometry.com), whose interest thus far has mostly focused on parametric design tools. These can be helpful for shape generation processes that incorporate panel properties. However, such a forward approach makes it very difficult to achieve the desired shapes and obtain a satisfactory paneling solution for sufficiently complex geometries[7].

Most previous work on the paneling problem deals with planar panels. Initial research in this direction dealt with special surface classes[8]. Covering general freeform surfaces with planar quad panels could be approached with methods of discrete differential geometry, and lead to new ways of supporting beam layout and the related computation of multi-layer structures[9]. More recently, this approach was extended to the covering of freeform surfaces by single-curved panels arranged along surface strips[10].

Buswell et al.[11] explored the issues surrounding design, data and process in terms of the impact of rapid manufacturing on the design and production of construction components. Guzik[1] considered the use of a particular digital fabrication method and studied the design-production relation and manufacturing parameters that can be integrated into the design process to facilitate 
design-to-production communication.

$\mathrm{CNC}$ milling has thus recently gained new applications in architecture. Three-or-more-axis milling machines can be used to form concrete moulds of freeform building elements. For example, this approach was applied in the construction of Zollhof Towers in Düsseldorf, Germany by Frank Gehry(2000). Over 350 individual facade elements were designed using CATIA software. The freeform components were milled in styrofoam by a numerically controlled machine, and then served as moulds for the reinforced concrete panels[1]. Corser[12] studied cases, the Dynaform(2001), the MARTa(2005) and the Kunsthaus Graz(2003), and discussed these in terms of each architect's design process and the engineering and fabrication issues.

These studies explored the possibilities of the design and generation of freeform buildings using BIM and manufacturing technologies. However, there are few studies that provide an in-depth case analysis of applied freeform surface design and construction. This study is an effort to analyze the pros and cons of each method for the concrete surface frame of the Tri-Bowl, and presents the implications and contributions related to the design and construction process of the freeform architecture.

\section{BIM Based Design and Considerations of Freeform Building}

\subsection{BIM Based Design of The Tri-Bowl}

The Tri-Bowl was constructed in commemoration of 'Global Fair \& Festival 2009, Korea' in Incheon-Songdo International City, Korea in 2010. The building was designed by iArch Architecture Company, and constructed by POSCO Construction Company. The building is a steel and reinforced concrete structure, and the envelope is constructed with aluminum panels and exposed concrete. The total area of the building is $2,892.95 \mathrm{~m}^{2}$.

The Tri-Bowl was not designed using traditional design processes and design software such as CAD, but with Rhino, a freeform curvature design modeling software, and CATIA, which is usually used in aerospace, automotive, ship building design and other applications. CATIA is very useful in surface creation and computer representation of surfaces.

With CATIA Frank Gehry was able to delineate in detail parts of buildings such as Bilbao Guggenheim Museum (Figure 1), his Barcelona fish sculpture (Figure 2) and others. Manufacturers and constructors can eliminate misunderstandings of a design and reduce the risk of construction error with CATIA.

For example, in Bilbao, the steel structure has no duplicate pieces of steel panels, everything is unique and it is a big structure. Using CATIA, however, the bid documents are clear and the subcontractors are all under budget. CATIA also enhanced the collaborative environment between architects, fabricators and the builders who executed the work.

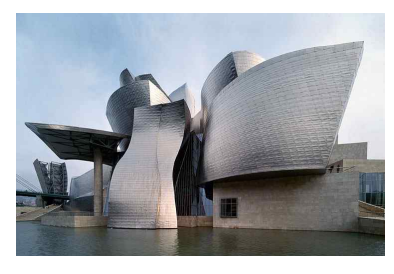

Figure 1. Guggenheim Museum (Spain, Bilbao, 1997)

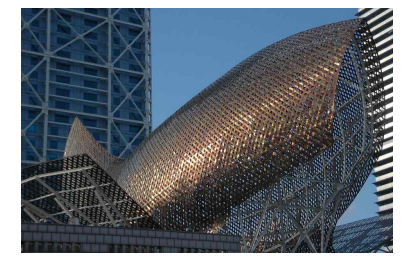

Figure 2. Fish (Spain, Barcelona, 1991)
The Tri-Bowl construction proceeded as follows. The surface was first segmented into more than 2,000 cells according to the architectural design. Structural analysis and design was then performed by calculating structural load of the segments and determining the structural system, concrete shell 
thickness, and bar size and arrangement according to the load. 3D modeling, which can be used to pre-build or virtually construct the structure, is also done in order to guarantee the constructability and the quality of the construction. In addition, post-tensioning is applied to compensate for the lack of steel for tension due to the thinness of the surface structure.

Mechanical design is also made based on the architectural design, and then the mechanical modeling is performed in order to identify the conflicts of multiple mechanical systems and other construction hardware such as walls, beams and others, as shown in Figures 3 and 4. Therefore, mechanical modeling; as well as structural and architectural design, is very important to check for constructability and construction problems before constructing the complex and diverse surface slabs of the Tri-Bowl.

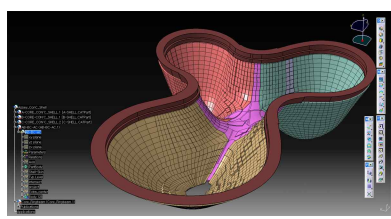

Figure 3. Concrete shell structure modeling in CATIA (Source: iArc \& Withworks)

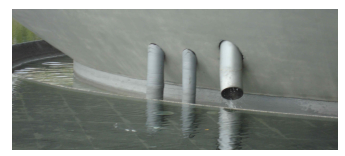

Figure 5. Rain water drainage

BIM technology, particularly CATIA, should be applied to numerically realize freeform design and construction. CATIA is based on the NURBS program, which has parametric attributes and thus controls the 3D geometry of curvature surface. CATIA enabled architects, manufacturers, and constructors to control 3D geometry curvatures composed of curtain wall, steel and concrete structure, and facilitated collaboration between the participants.

Utilizing BIM technology has major advantages for the Tri-Bowl construction in terms of saving money and time. An accurate BIM model of the Tri-Bowl benefited all members of the project team, as it allowed for a smoother and better-planned construction and reduced the potential for errors and conflicts between architectural engineering and MEP (Mechanical, Electronic, Plumbing) engineering.

As a result, the Tri-Bowl was designed, manufactured, and constructed thanks to such merits of Rhino and CATIA. The following sections will discuss the considerations and mock-ups for the freeform concrete design and construction of the Tri-Bowl. Figures 7 and 8 show the constructed figure of the Tri-Bowl.

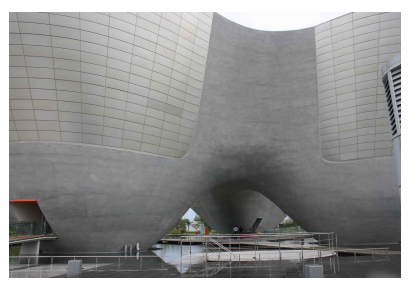

Figure 7. Concrete freeform figure of the Tri-Bowl

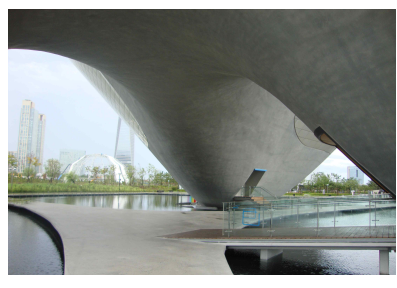

Figure 8. Concrete freeform figure of lower part of the Tri-Bowl

\subsection{Considerations and Mock-Ups for Freeform Concrete Surface Frame}

In order to establish the concrete surface frame of the Tri-Bowl, temporary work is first considered as a temporary supporting system and curving form work.

Three types of applicable form systems are considered according to the shell shapes and installed locations. The first one is a wood curvature form, applied to the building up to $6 \mathrm{~m}$ above the ground as shown in Figure 9. 


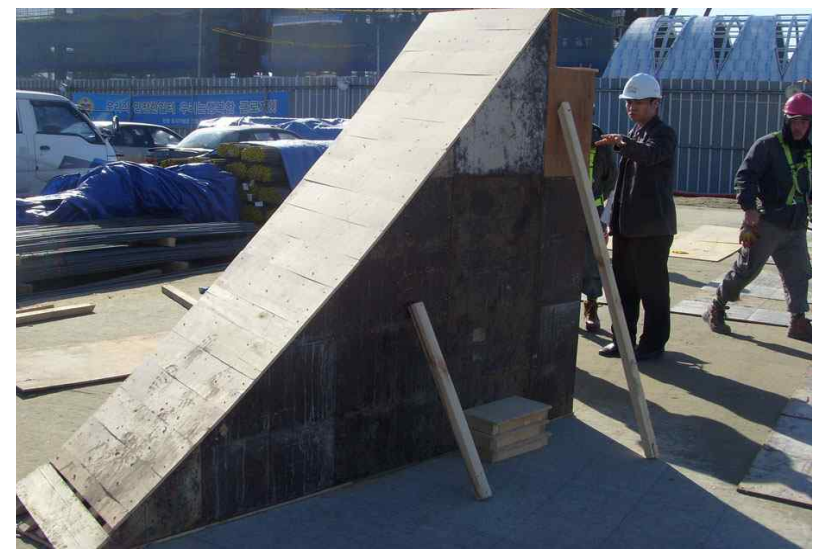

Figure 9. Wood curvature form for Tri-Bowl, up to $6 \mathrm{~m}$ above ground (first alternative)

The shell is divided and segmented to control the numeric values of the curvatures. The wood panel form is then made according to the section shapes of the segments. However, with the segmented wood panel form it is difficult to make different curvatures of the segments and the segmented area, particularly for the adjoining curved surfaces of concrete and metal panel, and thus precise geometry is required.

The second one is a metal curved form on the building above $6 \mathrm{~m}$ next to the center core structure as shown in Figure 10. However, it is very expensive. The total surface area of the metal curved form is about $1,600 \mathrm{~m}^{2}$.

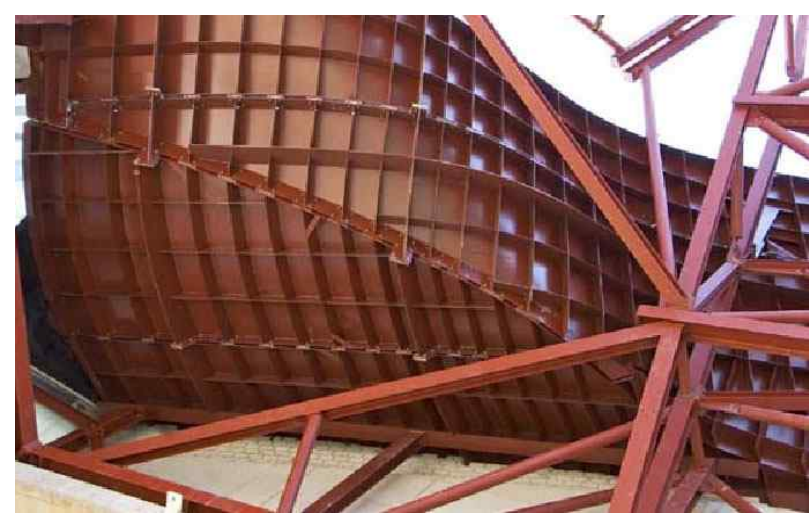

Figure 10. Metal curved form applied to the building above $6 \mathrm{~m}$ next to the center core structure (second alternative, MARTa Herford, Frank Gehry)
Thirdly, wood form or truss wall form was considered for planar parts on the building above $6 \mathrm{~m}$. Relatively speaking, this area is the easiest part in which to make the temporary support systems. As it is possible to make a developable surface that unrolls differently according to the curvature in the area, the segments are divided and then the shapes of each segment are generated in detail, and planar values are developed according to the gradient values of the curvature.

The yellow parts in Figure 11 are the wood form or truss wall area, while the green and blue parts are the metal curved form area.
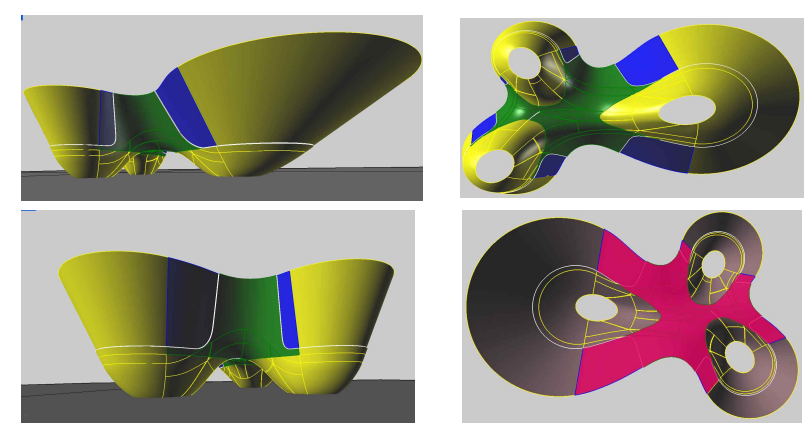

Figure 11. Form work planning of the Tri-Bowl

The red parts with irregular curvature are difficult to control numerically with traditional wood form. In addition, the entrances are needed for the work, but impact workability. A suitable form type is needed for temporary work considering the need for workability. The curvature of the above the ground is not consistent, while above $3.6 \mathrm{~m}$ it is the opposite. In the upper parts above $3.6 \mathrm{~m}$, the forms having regular curvature can be developed as segments, as shown in Figure 12.

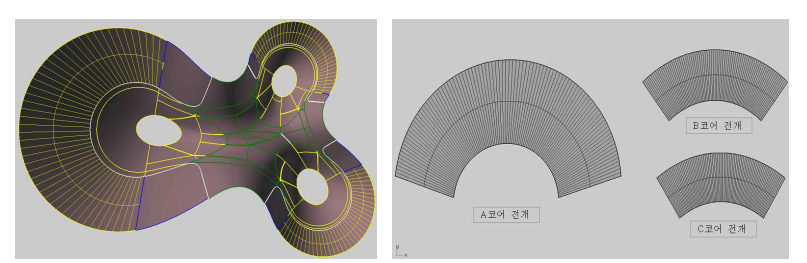

Figure 12. Form work segment plan and the developed forms 
In the segments above $6 \mathrm{~m}$, the entrance open space is planned by considering the connections of concrete finishes and metal panel, as shown in Figure 13.

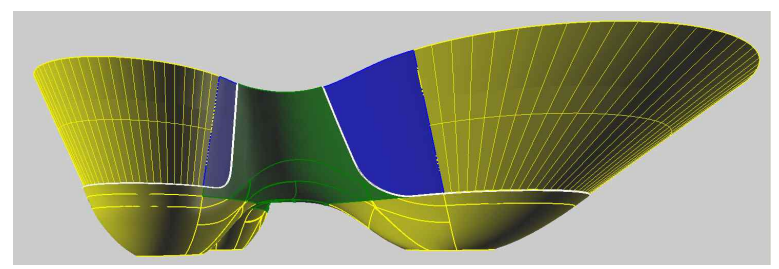

Figure 13. Entrance open space and the relationships of concrete and metal panel

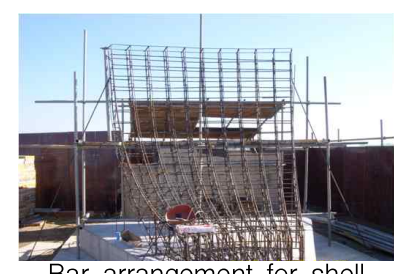

Bar arrangement for shell concrete structure mock-up

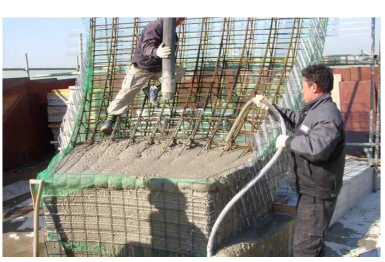

$1^{\text {st }}$ concrete pouring for shell concrete structure mock-up

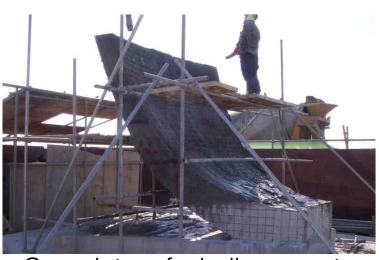

Complete of shell concrete structure mock-up

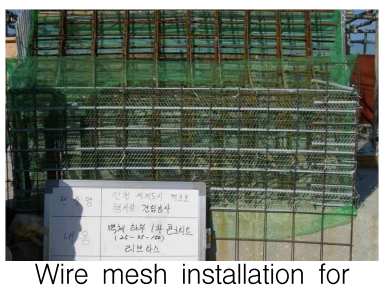
shell concrete structure mock-up

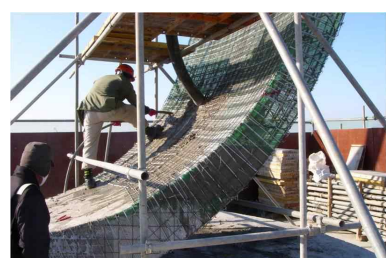

$2^{\text {nd }}$ concrete pouring for shell concrete structure mock-up

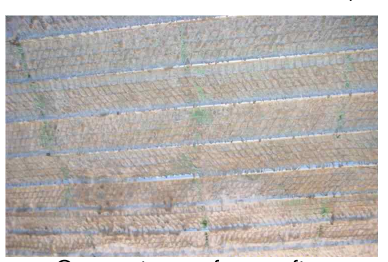

Concrete surface after releasing wire mesh
Figure 14. Truss- wall method for curved concrete surface of the Tri-Bowl envelope (third alternative)

Truss-wall method, the third alternative, is mocked up to construct the freeform concrete shell of the Tri-Bowl. The truss-wall method does not using traditional wood forms, but uses each vertically pre-manufactured curved steel bar according to the freeform curve line, and then free forms are made with wire mesh and metal lathe, as shown in Figure 14

The metal panels should be attached to the concrete frame of the building. The results of 1:1 truss-wall mock-up of freeform concrete frame, however, does not satisfy the requirement of making all of the vertical bars curved for the freeform concrete frame. Unfortunately, that is because the subcontractors lack experience with the technology. If the concrete frame of the freeform envelope is not constructed correctly, it can cause structural problems of the steel frame, connecting problems between concrete finishes and metal panels and so forth. The method for freeform concrete frame is thus reconsidered instead of the truss-wall method.

\section{Concrete Structure Work of Freeform Building}

\subsection{Temporary Work and Concrete work of Freeform Building}

Alternatives to the truss-wall method are considered due to the need for better constructability and the lack of experience. The first alternative method of temporary support is to use a temporary steel frame controlling all freeform shapes of the concrete shell structure as supports, as shown in Figure 15 and 16.

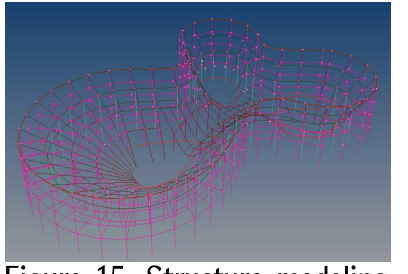

Figure 15. Structure modeling of temporary steel frame

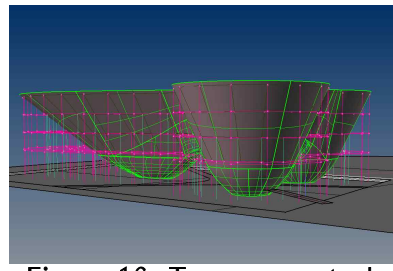

Figure 16. Temporary steel frame \& concrete surface
The temporary steel frame basically supports all freeform shapes and freeform wood form directly, as well as the concrete load and working load of 
the freeform structure. The temporary steel frame supports, however, were not actually applied due to the manufacturing cost and extended duration.

The other alternative using unit form or CNC section form is considered to make freeform concrete surfaces that control freeform shapes. The unit form method requires a great deal of wood materials because of the steeply inclined shapes of shell segments, while the CNC section form method can make freeform wood form shapes using the numeric values of section form regardless of the shell inclination. The CNC section form method can also reduce the wood material cost required for freeform shapes of the shell segments.

The wood truss is made and installed on the site based on the defined numeric values from 3D modeling in order to reduce the $\mathrm{CNC}$ manufacturing cost. The Tri-Bowl is shaped by the section forms based on the 48 sections of each bowl. In order to control freeform shapes of the center conjunctions of three bowls, 3D modeling defines each section for every $50 \mathrm{~cm}$, and made a yardstick point for construction by deducing vertical values at @500x@500 point of the shell, as shown in Figures 17 and 18.

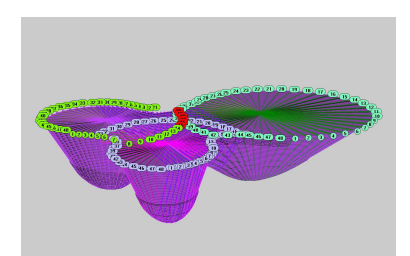

Figure 17. 3D modelling of section form

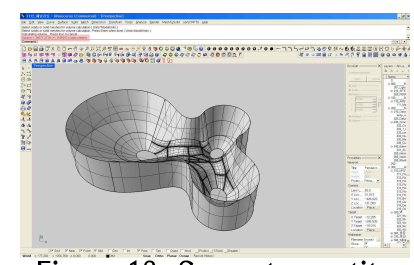

Figure 18. Support quantity take-off using 3D model
Temporary $\square-50 \times 50$ steel pipe cubic frame is supported to use as a benchmark of the 3D modeling numeric values for construction, as shown in Figure 19. Wood forms on the benchmark can support shell slabs for concrete pouring.
3D shop drawings (shown in Figure 20 as examples) are made for each $3 \mathrm{~m}$ height of the sections. Coordinate surveyors level and measure the points for section form installation based on the 48 sections of tree cores of the Tri-Bowl, as shown in Figures 21 and 22. Wood form work, bar arrangement, post-tensioning and concrete pouring are then performed, as shown in Figure 23.

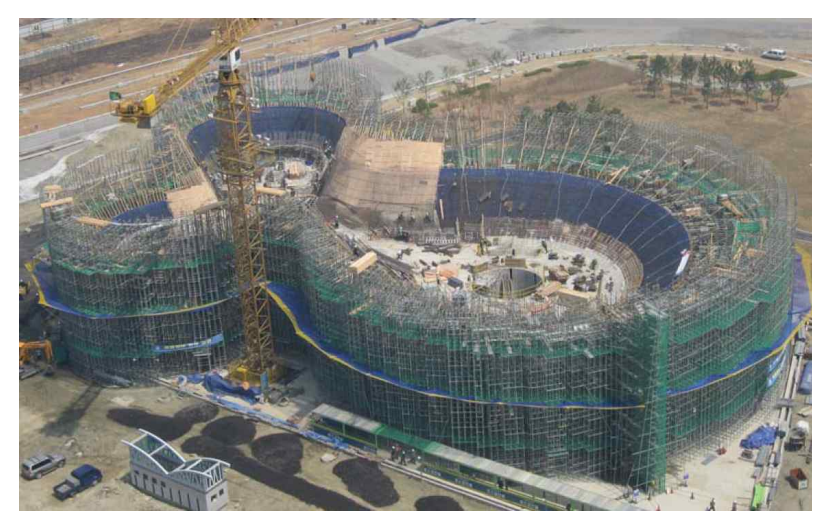

Figure 19. System support for form work

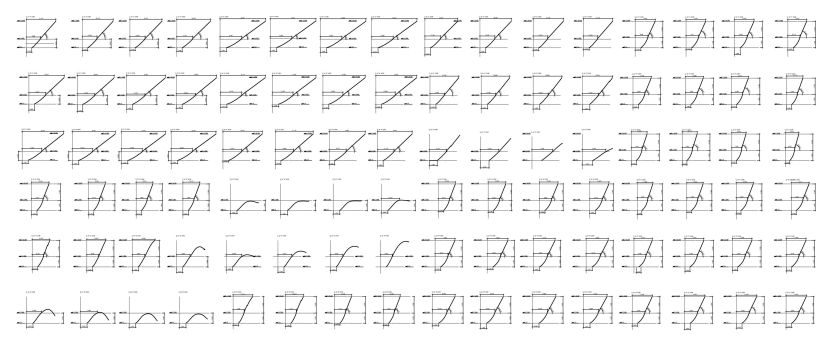

Figure 20. Examples of section form shop drawings

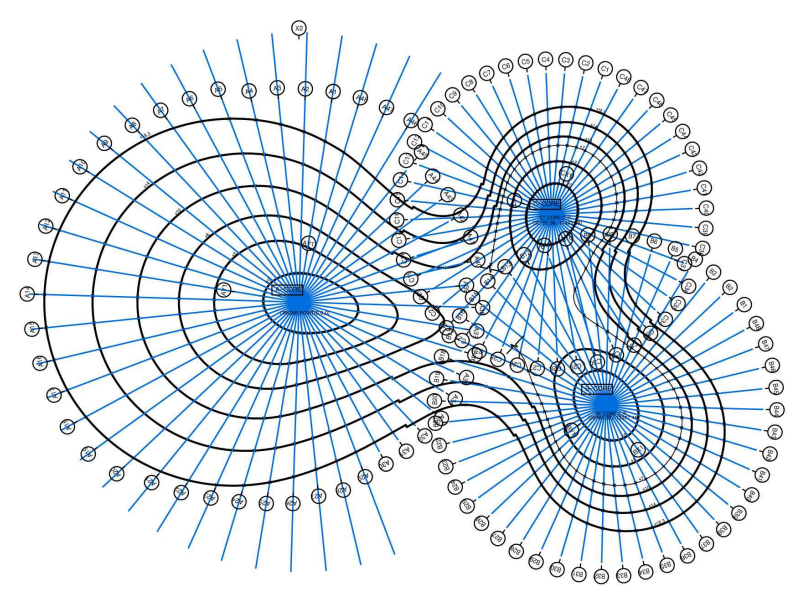

Figure 21. Coordinate data for section form installation 


\begin{tabular}{|c|c|c|c|c|c|c|}
\hline cordeVEL & 0.0 & 3.0 & 6.0 & 10.0 & 14.0 & 18.3 \\
\hline$A 1$ & 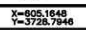 & 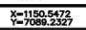 & 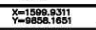 & 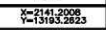 & 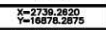 & 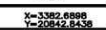 \\
\hline A2 & 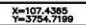 & 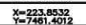 & 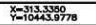 & 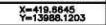 & 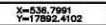 & 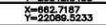 \\
\hline A3 & 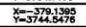 & 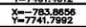 & 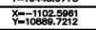 & 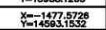 & 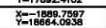 & 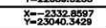 \\
\hline A4 & 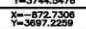 & 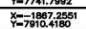 & 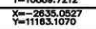 & 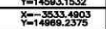 & 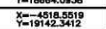 & 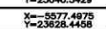 \\
\hline A5 & 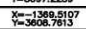 & 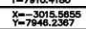 & 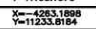 & 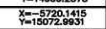 & 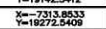 & 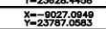 \\
\hline A6 & 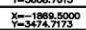 & 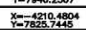 & 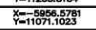 & 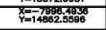 & 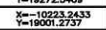 & 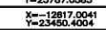 \\
\hline A7 & 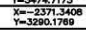 & 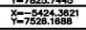 & 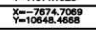 & 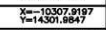 & 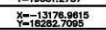 & 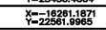 \\
\hline$A 8$ & 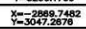 & 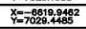 & 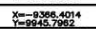 & 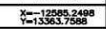 & 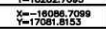 & 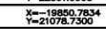 \\
\hline A9 & 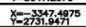 & 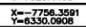 & 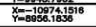 & 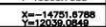 & 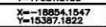 & 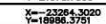 \\
\hline A10 & 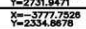 & 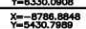 & 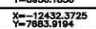 & 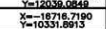 & 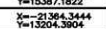 & 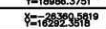 \\
\hline A11 & 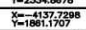 & 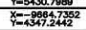 & 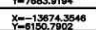 & 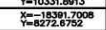 & 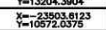 & 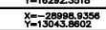 \\
\hline A12 & 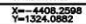 & 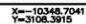 & 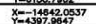 & $x=19097.14$ & 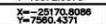 & 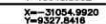 \\
\hline A13 & 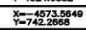 & 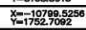 & 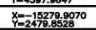 & 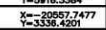 & 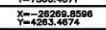 & 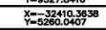 \\
\hline A14 & 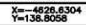 & 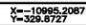 & 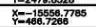 & 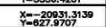 & 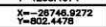 & 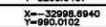 \\
\hline A15 & 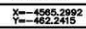 & 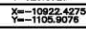 & 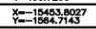 & 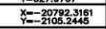 & 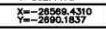 & 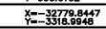 \\
\hline A16 & 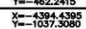 & 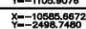 & 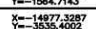 & 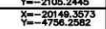 & 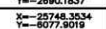 & 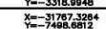 \\
\hline A17 & 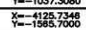 & 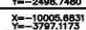 & 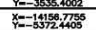 & 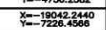 & 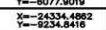 & 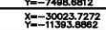 \\
\hline A18 & 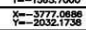 & 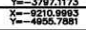 & 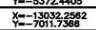 & 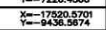 & 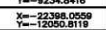 & 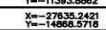 \\
\hline A19 & 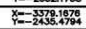 & 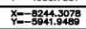 & 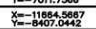 & 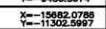 & 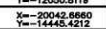 & 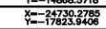 \\
\hline A20 & 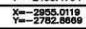 & 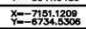 & 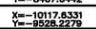 & 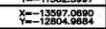 & 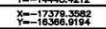 & 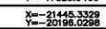 \\
\hline A21 & 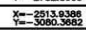 & 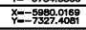 & 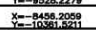 & 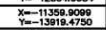 & 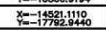 & 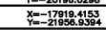 \\
\hline A22 & 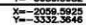 & 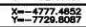 & 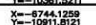 & 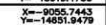 & 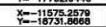 & 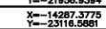 \\
\hline A23 & 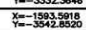 & 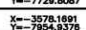 & 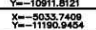 & 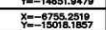 & 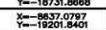 & 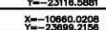 \\
\hline A24 & 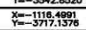 & 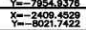 & 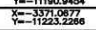 & 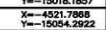 & 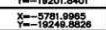 & 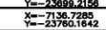 \\
\hline A25 & 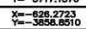 & 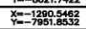 & 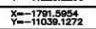 & 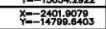 & 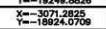 & 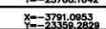 \\
\hline A26 & 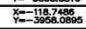 & 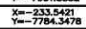 & 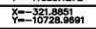 & 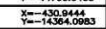 & 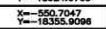 & 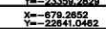 \\
\hline A27 & 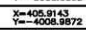 & 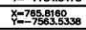 & 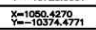 & 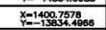 & 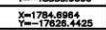 & 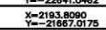 \\
\hline A28 & 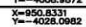 & 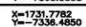 & $x=2039.94858$ & 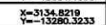 & 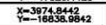 & 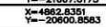 \\
\hline A29 & 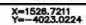 & 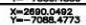 & 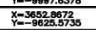 & 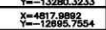 & 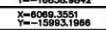 & 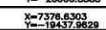 \\
\hline$A 30$ & 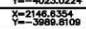 & 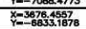 & 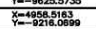 & 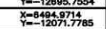 & 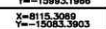 & 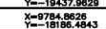 \\
\hline A31 & 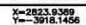 & 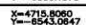 & 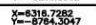 & 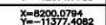 & 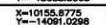 & 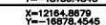 \\
\hline A32 & 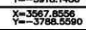 & 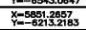 & 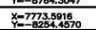 & 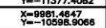 & 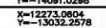 & 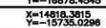 \\
\hline A33 & 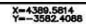 & 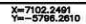 & 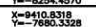 & 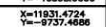 & 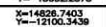 & 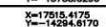 \\
\hline A34 & 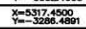 & 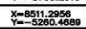 & 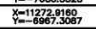 & 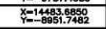 & 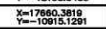 & 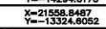 \\
\hline A35 & 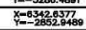 & 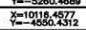 & 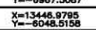 & 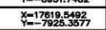 & 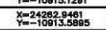 & \\
\hline A36 & 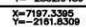 & 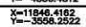 & 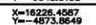 & - & 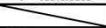 & \\
\hline A37 & 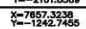 & 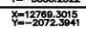 & 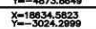 & & & \\
\hline A38 & 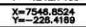 & 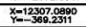 & 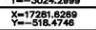 & 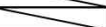 & 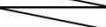 & 7 \\
\hline A39 & 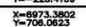 & $x=1007.5020100$ & 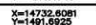 & & & \\
\hline A40 & 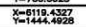 & 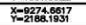 & 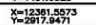 & 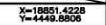 & ${ }^{\prime}$ & 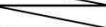 \\
\hline A41 & 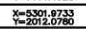 & 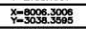 & 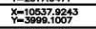 & 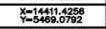 & 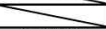 & E \\
\hline A42 & 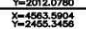 & 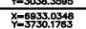 & 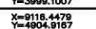 & 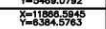 & 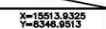 & \\
\hline A43 & 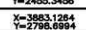 & 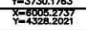 & 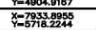 & 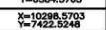 & 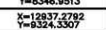 & 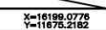 \\
\hline A44 & 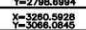 & 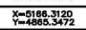 & 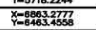 & 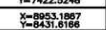 & 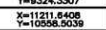 & 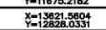 \\
\hline A45 & 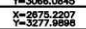 & 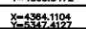 & 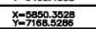 & 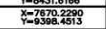 & 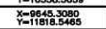 & 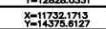 \\
\hline A46 & 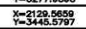 & 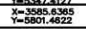 & 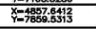 & 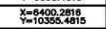 & 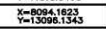 & 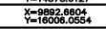 \\
\hline A47 & 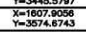 & 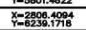 & 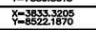 & 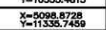 & 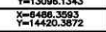 & 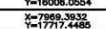 \\
\hline A48 & 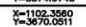 & 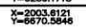 & 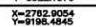 & 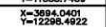 & 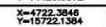 & 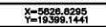 \\
\hline
\end{tabular}

Figure 22. Example of coordinate values for section form installation

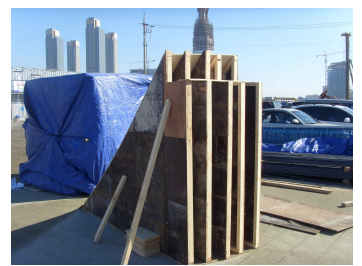

Unit form mock-up

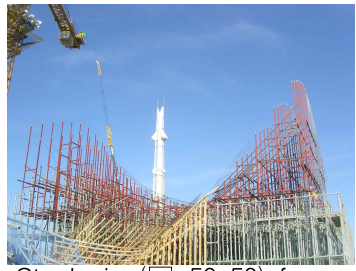

Steel pipe $(\square-50 \times 50)$ frame installation

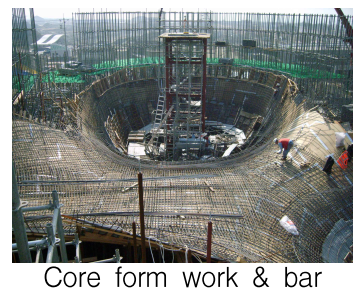
arrangement

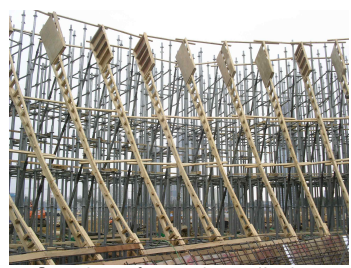

Section form installation
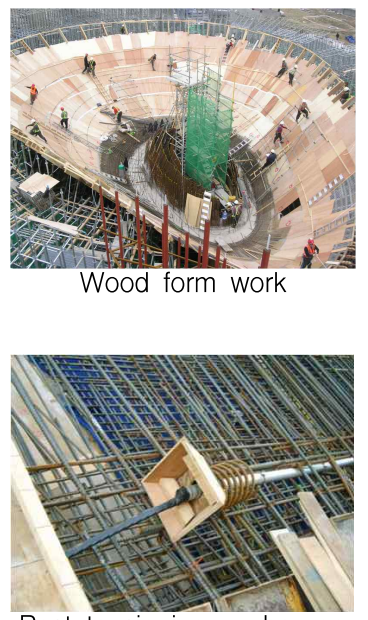

Post-tensioning anchorage hardware

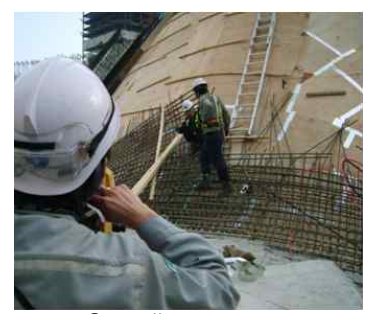

Coordinate curve

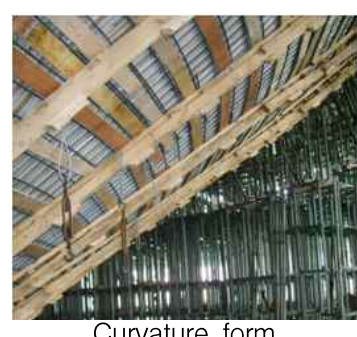

Curvature form

Figure 23. Temporary work and concrete work process

\subsection{Concrete Finishes of Freeform Building}

The concrete finishing method is finally applied using CNC section form and wood truss temporary work. While previously considered surface finishes are GFRC (Glass Fiber Reinforced Concrete) based on the truss-wall method, the section form and temporary wood form can supply more elegantly exposed concrete surfaces using little surface treatment without concrete pouring or plastering, thus enhancing the constructability and construction quality.

In addition, the relevant clearance of the two abutting surfaces of concrete and metal panel is changed from $15 \mathrm{~cm}$ to $25 \mathrm{~cm}$ of the previously defined error tolerance. In other words, securing distances between concrete finishes and panel finishes, the maximum permissible error tolerance is increased for smooth face-to-face contact of the different materials. The results of concrete finishes of the Tri-Bowl after support and form release are shown in Figures 24 and 25.

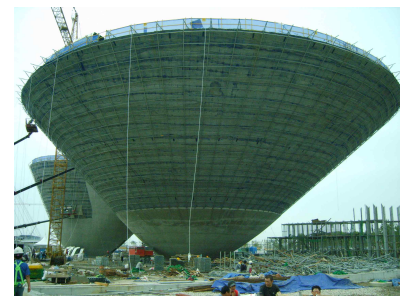

Figure 24. Front view after support and form release

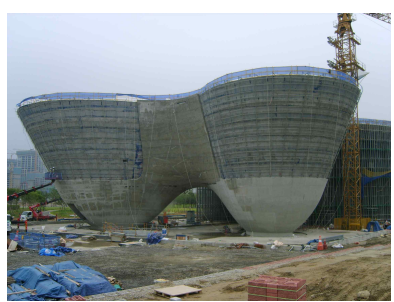

Figure 25. Side view after support and form release 


\section{The Lessons Learned}

The digital age is making a very different kind of freeform architecture possible, and at the same time, is providing unprecedented opportunities for a significant redefinition of the production of freeform architecture. In fact, there are some lessons learned and implications of the Tri-Bowl compared with the traditional production system, particularly for design and construction of the freeform concrete frame.

We considered three methods for the design and construction of the freeform concrete frame of the Tri-Bowl. The first one is the wood curvature form, which uses segmented wood panels that secure the curve line of the shape. However, the method is difficult to generally apply, and is unsuitable for wood panel forms that need double-curved curvatures for various segments. The metal curvature form was thus considered next, but it is also unsuitable in terms of the manufacturing cost. The truss-wall method that uses each vertically pre-manufactured curved steel bar according to freeform curve line and then makes free forms with wire mesh and metal lath was considered. The results of 1:1 truss-wall mock-up of freeform concrete frame, however, did not satisfy the need to make all vertical bars curved bars for freeform concrete frame. CNC section form and temporary $\square-50 \times 50$ steel pipe cubic frame are thus considered instead of truss-wall method due to the need for constructability and a lack of experience.

The CNC section form method can be used to make freeform wood form shapes regardless of shell inclination based on the numeric values of the section form. The CNC section form can reduce the wood material cost for each shell segment in a continuous concrete pour. The wood truss is made and installed on the site based on the numeric values defined through 3D modeling in order to reduce the $\mathrm{CNC}$ manufacturing cost.

3D modeling defines each section by $50 \mathrm{~cm}$ and made a yardstick point for construction by deducing vertical values at @500x@500 point of the shell. Temporary $\square-50 \times 50$ steel pipe cubic frame is also supported in order to use as a benchmark of the 3D modeling numeric values for construction.

As a result, precise manufacturing and installation for freeform building is performed based on the exact numerical values of materials, particularly the temporary steel pipe cubic frame and the CNC section form, and installation was facilitated through BIM 3D technology such as CATIA and Rhino. The freeform concrete frame should be perfectly built in a manner that maintains the curving surface because the freeform concrete envelope directly adjoins the aluminum curvature panels.

3D modeling allows the participants to understand what is really to be constructed. After determining the constructability through the virtual construction of the Tri-Bowl, the mock-ups are tested in order to secure the economy of material and construction cost and quality of the freeform shapes.

In addition, the previous design and construction process should be changed, and a good quality of surface frame, such as concrete or steel frame, is required for the freeform envelope. In the previously used process of regular panel manufacturing and installation, shop drawings are made based on the actual on-site measurement on the surface frame and then installed on the surface frame. However, more difficult shop drawings are made for the freeform envelope after an actual on-site survey on the surface frame. The shop drawings should thus be precisely determined before making the surface frame. In 
other words, the freeform surface frame should be maintained with exact numeric value and good quality of curving shapes. As a result, the freeform concrete frame of the Tri-Bowl is exactly constructed using the CNC section form method after all methods are considered and mocked up using numerical values on the exact installation coordinates on-site.

\section{Conclusions}

We studied BIM based design and considerations for freeform building. This paper describes the pros and cons related to mock-ups for freeform concrete surface frame, temporary work, concrete work and concrete finishes of freeform building.

Most of all, for the freeform building it is important to have close collaboration among different participants, such as architect, structure engineer, MEP engineer, manufacturer, and contractor. Well-structured collaboration allows virtual conditions to be coped with as the Tri-Bowl is constructed.

\section{Acknowledgement}

This research was supported by Basic Science Research Program through the National Research Foundation of Korea(NRF) funded by the Ministry of Education, Science and Technology (No. 2011-0004346).

\section{References}

1. Guzik A. Digital fabrication inspired design: Influence of fabrication parameters on a design process [master's thesis]. London (UK): University College London; 2009. 71 p.

2. Schodek D, Bechthold M, Griggs K, Kao KM, Steinberg M. Digital design and manufacturing - CAD/CAM application in architecture and design, Hoboken (Belgium): John Wiley \&
Sons, Inc.; 2005. p. 13.

3. Kim E, Park J, Jun H. Deformed building design and fabrication based on the parametric technology. The 3rd International Conference on Construction Engineering and Management / The 6th International Conference on Construction Project Management(ICCEM/ICCPM 2009); 2009 May 27-30; Jeju, Korea. Seoul (Korea): KICEM; c2009. p. 1107-12.

4. Park J, Lim H, Lee M. A basic study on an envelope design for sustainable architecture based on BIM(Building Information Modeling); Proceeding of Annual Conference of the Architectural Institute of Korea; 2009 October 23-24; Kwangwon. Seoul (Korea); AIK; 2009. p. 225-8.

5. Park J, Lee MA. A study on the application of BIM(Building information modeling) in the field of non-linear forms architecture. Proceeding of Annual Conference of the Architectural Institute of Korea; 2008 October 24-25; Gwangju. Seoul (Korea); AIK; 2008. p. 209-12.

6. Park H, Jun H. A study on generation method of free-form architecture through a planar quadrilateral mesh technique. The Korean Institute of Culture Architecture Journal. 2009 June:26:5-12.

7. Eigensatz M, Kilian M, Schiftner A, Mitra N, Pottmann H, Pauly M. Paneling Architectural Freeform Surfaces. Proceedings of Association for Computing Machinery Transactions on Graphics; 2010 July 25-29; Los Angeles Convention Center. Los Angeles (CA): ACM Transactions on Graphics; 2010. Article 45.

8. Glymph J, Shelden D, Ceccato C, Mussel J, Schober H. A parametric strategy for free-form glass structures using quadrilateral planar facets. Automation in Construction. 2004 Mar;13(2):187-202.

9. Pottmann H, Liu Y, Wallner J, Bobenko AI, Wang W. Geometry of multi-layer freeform structures for architecture. Proceedings of Association for Computing Machinery Transactions on Graphics; 2007 August 5-9; San Diego Convention Center. San Diego (CA): ACM Transactions on Graphics; 2007. Article 65.

10. Pottmann H, Schiftner A, Bo P, Schmiedhofer H, Wang W, Baldassini N, Wallner J. Freeform surfaces from single curved panels. Proceedings of Association for Computing Machinery Transactions on Graphics; 2008 August 11-15; Los Angeles Convention Center. Los Angeles (LA): ACM Transactions on Graphics; 2008. Article 76.

11. Buswell RA, Thorpe A, Soar RC, Gibb AGF. Design, data 
and process issues for mega-scale rapid manufacturing machines used for construction. Automation in Construction. 2008 Nov;17(8):923-9.

12. Corser R. Fabricating architecture(selected readings in digital design and manufacturing). New York (NY): Rinceton Architectural Press; 2009. p. 111. 